University of New Hampshire

University of New Hampshire Scholars' Repository

Center for Coastal and Ocean Mapping

Center for Coastal and Ocean Mapping

$6-2010$

\title{
New Approaches for Evaluating Lidar-Derived Shoreline
}

\author{
Christopher Parrish \\ University of New Hampshire, Durham \\ Stephen A. White \\ University of New Hampshire, Durham \\ Brian R. Calder \\ University of New Hampshire, Durham, brian.calder@unh.edu \\ Shachak Pe'eri \\ University of New Hampshire, Durham, shachak.peeri@unh.edu \\ Yuri Rzhanov \\ University of New Hampshire, Durham, Yuri.Rzhanov@unh.edu
}

Follow this and additional works at: https://scholars.unh.edu/ccom

Part of the Oceanography and Atmospheric Sciences and Meteorology Commons

\section{Recommended Citation}

Parrish, Christopher; White, Stephen A.; Calder, Brian R.; Pe'eri, Shachak; and Rzhanov, Yuri, "New Approaches for Evaluating Lidar-Derived Shoreline" (2010). Imaging and Applied Optics Congress. 780.

https://scholars.unh.edu/ccom/780

This Conference Proceeding is brought to you for free and open access by the Center for Coastal and Ocean Mapping at University of New Hampshire Scholars' Repository. It has been accepted for inclusion in Center for Coastal and Ocean Mapping by an authorized administrator of University of New Hampshire Scholars' Repository. For more information, please contact Scholarly.Communication@unh.edu. 


\title{
New Approaches for Evaluating Lidar-Derived Shoreline
}

\author{
Christopher E. Parrish ${ }^{\dagger}$, Stephen A. White ${ }^{\dagger}$, Brian R. Calder ${ }^{\ddagger}$, Shachak Pe’eri ${ }^{\ddagger}$, Yuri Rzhanov ${ }^{\ddagger}$ \\ $†$ NGS Remote Sensing Division, NOAA/NOS, National Geodetic Survey, Silver Spring, MD 20910, USA \\ ${ }^{\ddagger}$ Center for Coastal and Ocean Mapping, University of New Hampshire, Durham, NH 03824, USA
}

\begin{abstract}
This study presents and compares two new methods of assessing the uncertainty of lidar-derived National Shoreline mapped by NOAA's National Geodetic Survey: an empirical (ground-based) approach and a stochastic (Monte Carlo) approach.

OCIS codes: (280.3640) Lidar; (120.2830) Height measurements; (000.4430) Numerical approximation and analysis
\end{abstract}

\section{Introduction}

NOAA's National Geodetic Survey (NGS) is mandated to map the National Shoreline, which is portrayed on NOAA nautical charts and treated as the legal shoreline by many U.S. agencies [1]. Although the primary use of this tidedatum-based shoreline is in support of safe navigation, the data are also being used in an increasingly wide range of coastal science applications, including understanding and responding to climate change threats, such as sea level rise, and shoreline erosion. Over the past decade, NOAA has made significant advancements in shoreline mapping, including developing, testing, and implementing airborne light detection and ranging (lidar) shoreline mapping procedures [2]. Benefits of the lidar-based procedures include increased automation, reduction of the subjectivity inherent in the conventional photogrammetric shoreline mapping process, and provision of multi-use coastal elevation datasets.

Methods for analyzing the uncertainty of the mapped shoreline have lagged behind development of the new mapping technologies and techniques, however. These uncertainty estimates are critical for all of the following: a) satisfying the latest international standards established by the hydrographic surveying community [3]; b) analyzing uncertainty in derived estimates being generated by coastal scientists, such as shoreline change rates; and c) informing policy decisions within NGS' Coastal Mapping Program. To this end, we conducted a study to develop, test, and compare new methods of lidar-derived shoreline uncertainly analysis. The first approach we tested is a field-survey technique that provides uncertainty estimates based on high-precision integrated GPS and laser level systems. While extremely accurate, this method is also expensive and time consuming, making it infeasible for large-scale deployment. Thus, the second approach is a stochastic technique using Monte Carlo simulation and estimates of the uncertainty in each observable in the lidar system. Preliminary results show good agreement between the two approaches.

\section{Methods}

The data collection for this work was conducted along the North Carolina Outer Banks in 2008 as part of NOAA's Integrated Ocean and Coastal Mapping (IOCM) initiative [4]. The airborne data included topographic lidar data acquired with an Optech ALTM 3100, and high-resolution, four-band (NIR, R, G, B) digital imagery collected with an Applanix DSS DualCam directly-georeferenced aerial camera. A mean high water (MHW) shoreline vector was extracted from the lidar data following the procedures outlined in [2]. Concurrent field work included acquisition of GPS ground control points for assessing the accuracy of the lidar data and aerial imagery. Additionally, profiles perpendicular to the shoreline (transects) were surveyed for empirical assessment of the lidar-derived shoreline uncertainty. The transects were surveyed at $\sim 10 \mathrm{~m}$ spacing with a Topcon Laser-Zone integrated laser level and realtime GPS system. The horizontal positioning was performed at the centimeter-level using the Real-Time Kinematic (RTK) GPS component of the system, based on a horizontal NAD83 (CORS96) position. The heights of the shoreline transect points, relative to the MHW tidal datum, were established using the laser-level component of the system with direct ties to local tidal benchmarks. The quantitative assessment of lidar-derived shoreline positional accuracy was conducted by interpolating the Topcon Laser-Zone transects to determine the MHW zero-crossing point for each transect, and then computing the Euclidean distance from each MHW ground-truth point to the lidarderived shoreline vector, as shown in Fig. 1. 


\section{OMC5.pdf}
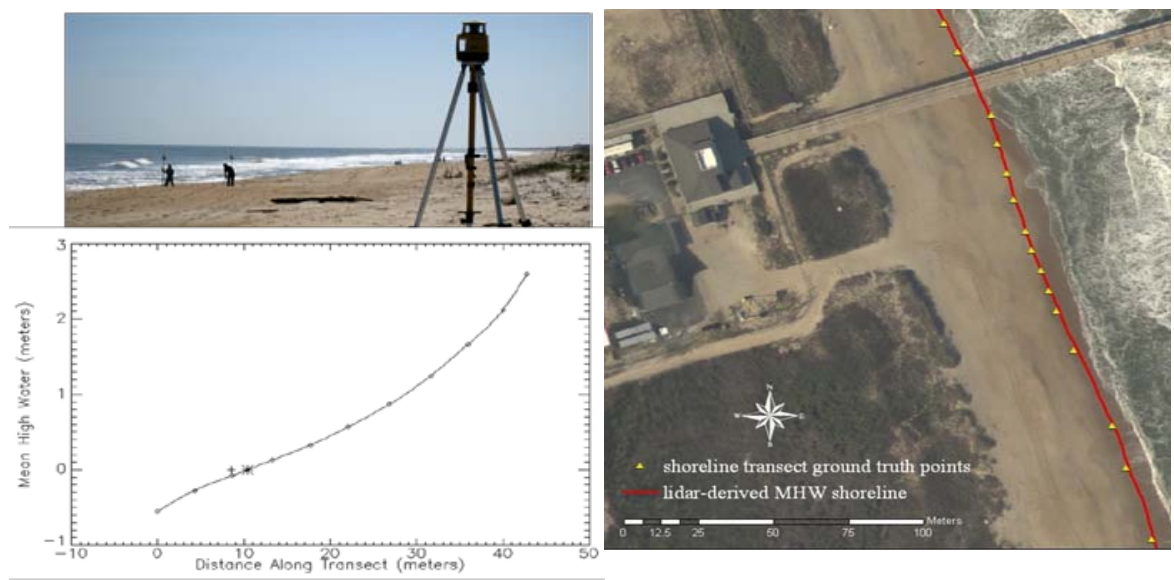

Fig. 1: Ground truth collected with integrated RTK-GPS-laser-level system along shoreline transects.

In parallel with the empirical (field-survey-based) uncertainty analysis, we conducted a statistical evaluation of uncertainty from first principles using the Monte Carlo method. Our approach entails focusing on likely uncertainties of the fundamental lidar measurements (e.g., roll, pitch, heading, range, scan angle, latency angle, torsion coefficient, northing, easting and altitude) and propagating these uncertainties through the normal equations and methods used to estimate the shoreline. The outline of the method is depicted in Fig 2. A trial dataset over the study site is the reference DTM for the Monte Carlo simulation. The shoreline derived from the trial dataset is considered the "nominal shoreline." We first back-project the resolved elevations from the trial dataset through the laser geolocation equation in order to determine the indicated range and angles resolved by the lidar during flight. We then model the potential uncertainties of positioning, attitude measurement, range, and angle determination in order to model a series of "plausible" estimates of possible observed datasets. These are then processed through all of the normal geolocation, DTM construction, and shoreline extraction code, and an ensemble of shorelines is constructed. The nominal shoreline is then compared directly to the plausible ensemble in order to estimate the product uncertainty of the shoreline.

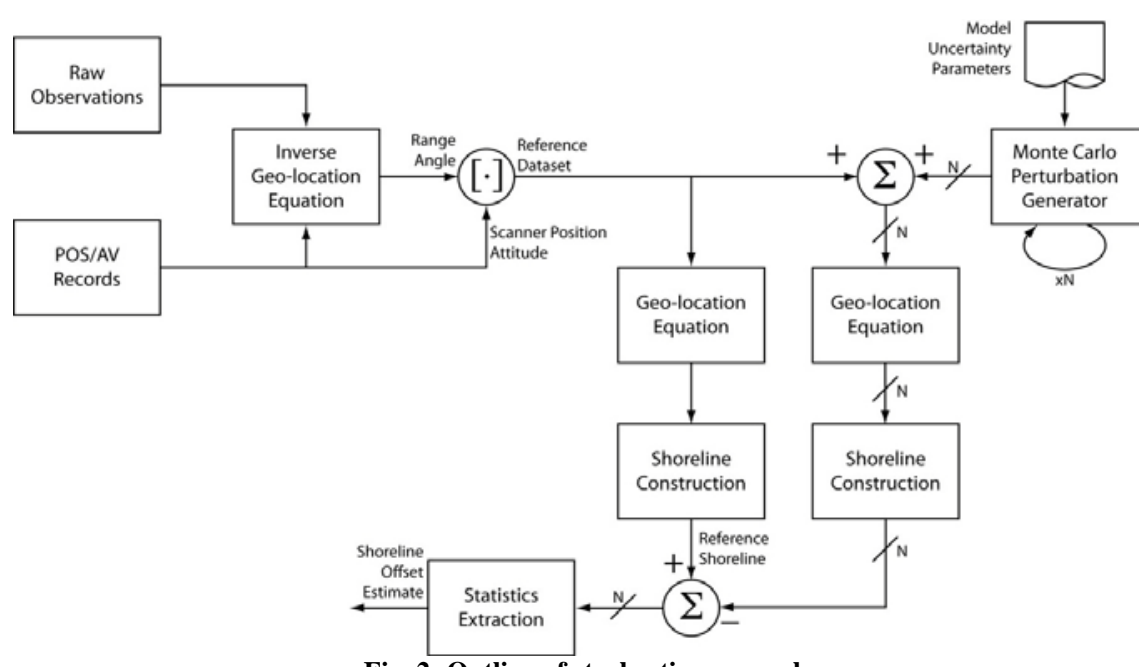

Fig. 2: Outline of stochastic approach.

After processing, we assess the offset between contours in the ensemble and the reference shoreline. We then accumulate statistics of the orthogonal distance from the reference shoreline to the ensemble shorelines along the normal at each test point as a summary of the horizontal shift of the members of the ensemble, and therefore of the horizontal uncertainty of the product shoreline under test. The distributions of orthogonal offsets about the reference shoreline can be determined directly from the ensemble (Fig. 3). A metric summarizing the uncertainty of the shoreline can be constructed by considering an appropriate confidence interval (e.g., 95\% CI) on the orthogonal offsets. 


\section{OMC5.pdf}



Fig. 3: Examples of distribution of offsets; the distribution at $\mathrm{t}=\mathbf{0 . 4 6}$ (top right) is an outlier caused by non-shoreline data in the dataset about a pier mid-way up the beach.

\section{Discussion and Conclusions}

Both methods of assessing uncertainty in NGS' lidar-derived National Shoreline investigated in this research were shown to have distinct advantages. The integrated laser-level-RTK-GPS technology used in the field-based approach was found to work quite well for this type of uncertainty analysis, providing high-accuracy 3D spatial coordinates and tidally-referenced heights along numerous shoreline transects. Furthermore, by leveling from a tidal benchmark, we were able to obtain ground truth data free from any uncertainty associated with vertical datum transformations or water level observations.

However, since it is infeasible to conduct ground-truth surveys for each and every shoreline mapping project, the stochastic method is advantageous from an operational perspective. Our analysis of the Monte Carlo-based uncertainty assessment indicates that the results are consistent with those determined through the field campaign, showing uncertainties on the order of 1.0-1.5 m (95\%) over much of the shoreline with local increases to as much as $3.3 \mathrm{~m}(95 \%)$ in specific locations. Strong correlation is observed between the shoreline uncertainty and the shoreline slope; for a given vertical uncertainty, a larger horizontal uncertainty is observed in areas with smaller slope. The similarity of results obtained with the two methods is encouraging, as it indicates that, in the future, NGS may be able to utilize the Monte-Carlo approach operationally to assess the positional uncertainty in its lidar-derived shoreline.

\section{References}

[1] D. Graham, M. Sault, and J. Bailey, 2003. National Ocean Service Shoreline-Past, Present, and Future. Journal of Coastal Research, S.I. No. 38, pp. 14-32.

[2] S. White, 2007. Utilization of LIDAR and NOAA's Vertical Datum Transformation Tool (VDatum) for Shoreline Delineation. Proceedings of the Marine Technology Society / IEEE OCEANS Conference. Vancouver, BC.

[3] International Hydrographic Organization (IHO), 2008. IHO Standards for Hydrographic Surveys, 5th edition., Monaco: International Hydrographic Bureau, 36p.

[4] G. Scott, N. Wijekoon, and S. White, 2009. Multi-sensor Mapping: Integrating Data Streams for Coastal Science and Management. Hydro International, 13(2), 20-23. 